\title{
MAHASISWA IAIN KEDIRI DAN DOMINASI TEKNOLOGI HERBERT MARCUSE
}

\author{
A Zahid', Rista Aulia Sholikhah, Siti Mariyam \\ UIN Sayyid Ali Rahmatullah Tulungagung ${ }^{1}$
}

\begin{abstract}
Modern society has unknowingly been dominated by modern technology which makes humans passive and uncritical of social conditions, as well as receptive. That people no longer live with technology, but is controlled by technology, this rationality can be seen when cellphones do not have a connection to the internet, it can be said that they will be out of date because they cannot update the latest information. This becomes an interesting discussion because it is almost felt by students, especially students of IAIN Kediri. This research uses a critical study of Herbert Marcuse's technological rationality which leads to one-dimensional humans or commonly referred to as One Dimensional Man. Therefore, this study seeks to explain the phenomena that occur among students related to meeting the needs of data packages that can affect various aspects of their daily lives. The results of this study are the need for a data package for the students of IAIN Kediri as a primary need. This is because with the data package students are able to find out the latest information on matters related to lectures, on the other hand, with the student data package, smartphones are also dominated by various features in it
\end{abstract}

Keywords : Dominance of Technology, Rationality of Technology, One Dimensional Man.

\begin{abstract}
Abstrak
Masyarakat modern tanpa sadar telah didominasi oleh teknologi modern yang menciptakan manusia menjadi pasif berkarya dan tidak kritis terhadap kondisi sosial, serta reseptif. Bahwasannya masyarakat sudah tidak lagi hidup dengan teknologi, namun sudah dikontrol oleh teknologi, rasionalitas ini dapat dilihat saathandphone tidak memiliki koneksi terhadap internet, maka dapat dikatakan bahwa mereka akan ketinggalan zaman karena tidak bisa update akan berbagai macam informasi terbaru. Hal ini menjadi suatu bahasan yang menarik karena hampir dirasakan olehmahasiswa khususnya mahasiswa IAIN Kediri. Penelitian ini menggunakan studi kritis rasionalitas teknologi Herbert Marcuse yang mengarah kepada manusia berdimensi satu atau biasa disebut dengan One Dimensional Man. Oleh karenanya, penelitian ini berusaha menjelaskan fenomena yang terjadi di kalangan Mahasiswa terkait dengan pemenuhan kebutuhan paket data yang dapat mempengaruhi berbagai aspek dalam kehidupan sehari-hari mereka. Adapun hasil penelitian ini adalah kebutuhan akan paket data pada Mahasisa IAIN Kediri sebagai kebutuhan yang primer. Hal ini dikarenakan dengan adanya paket data mahasiswa mampu mengetahui informasi terbaru mengenai hal-hal yang berhubungan dengan perkuliahan, sisi lain dengan adanya paket data mahasiswa juga terdominasi oleh smartphonedengan berbagai fitur didalamnya
\end{abstract}

Kata Kunci : Dominasi Teknologi, Rasionalitas Tekonologi, Manusia Satu Dimensi.

11azahidwaris19@gmail.com 


\section{Pendahuluan}

Era modern merupakan suatu hal yang tidak akan pernah habis jika diperbincangkan. Pada awalnya, semangat untuk mencapai era modern adalah pencapaian tingkat sosial yang disebut dengan kemajuan. Sehingga alat yang digunakan untuk mencapai kemajuan tersebut tidak lain tidak bukan adalah rasionalitas, kemajuan teknologi dan sains (Marcuse, 1964:123-124).Kemajuan teknologi membawa sekaligus dampak positif serta negatif. Di sisi positif kemajuan teknologi dan sains menciptakan optimisme akan kehidupan yang lebih baik bagi manusia (Pratama, 2019:198-226). Kemajuan teknologi dianggap sebagai cahaya terang yang menyelamatkan dari kelangkaan dan kemiskinan, menjauhkan dari keterbelakangan, memberikan kemudahan dalam memenuhi kebutuhan hidup, dan kebebasan dari ketergantungan terhadap alam. Namun di sisi yang lain, era modern tidak hanya memberikan kemajuan bagi umat manusia, namun juga mengarahkan kepada sisi-sisi gelap lain yang bisa juga menjadi titik yang mengantarkan manusia kepada kehancuran (Zahid, 2019:1-15). Tidak hanya itu, kemajuan ini akhirnya memberikan kemudahan yang sebenarnya menciptakan neraka bagi sesama manusia dan alam semesta.

Melihat realita yang sedang terjadi sekarang, era modern dengan kemajuan teknologi nya sudah sangat mendominasi bahkan sudah seperti suatu kebutuhan yang harus terpenuhi setiap harinya. Ketika seseorang tidak dapat mengakses internet misalnya, maka akan ada sesuatu yang mengganjal, misalnya dia merasa tidak bisa update akan informasi terbaru, entah itu dalam aspek hiburan saja atau kepentingan yang lebih urgent berhubungan dengan tugas contohnya jika dihubungkan dengan kehidupan mahasiswa. Maka internet menjadi suatu hal yang wajib ada, akan tetapi dalam jurnal ini tidak akan membahas mengenai bagaimana internet tersebut mendominasi, namun lebih kepada akarnya yakni pemenuhan akan paket data seluler yang 
menjadi akar adanya akses internet terhadap smarthphone yang saat ini sudah menjadi kebutuhan primer, selain kebutuhan makan atau kebutuhan lain.

Penelitian ini menggunakan analisis kritis rasionalitas teknologi Herbert Marcuse, Dikarenakan berhubungan dengan kondisi sosial mahasiswa IAIN Kediri yang menempatkan konsumirisme akan kebutuhan paket data sebagai kebutuhan yang primer. Sebagai mahasiswa yang hidup di era perkembangan teknologi, konsekwensi atas hadirnya smartphone berimbas pada kebutuhak paket data. Dalam hal ini Marcusem melihat imbas dari teknologi yang hendak membebeaskan manusia dari paradigma klasik, sehingga terperangkap pada dominasi teknologi atas manusia sendiri. Kebutuhan paket data berjalan selaras dengan smartphone sehingga Marcuse melihat ada dominasi teknologi yang dalam hal ini, dirasakan oleh mahasiswa IAIN Kediri.

Marcuse juga berpendapat bahwa masyarakat modern merupakan masyarakat yang tidak sehat, situasi inilah yang disebut dengan masyarakat berdimensi satu atau One Dimensional Man, hal ini menjadi ktitikan atas masyarakat industri maju yang teknokratis yang membawa dampak kepada problematika dehumanisasi. Masyarakat modern secara tanpa sadar telah didominasi oleh teknologi modern yang menciptakan manusia menjadi tidak kreatif dan tidak kritis terhadap kondisi sosial, dominasi tersebut secara tidak langsung dirasakan dan tanpa disadari oleh masyarakat sebagai suatu yang tidak wajar.Tujuan penelitian ini adalah untuk mengetahui bagaimana sebenarnya pemenuhan kebutuhan akan paket data seluler menjadi suatu hal yang primer dikalangan mahasiswa IAIN Kediri, bagaimana dampaknya jika mereka tidak memiliki akses intenet, bagaimana kebutuhan akan paket data seakan-akan mengontrol mereka untuk selalu update akan akses terhadap internet. 


\section{Metode Penelitian}

Penelitian ini dilakukan dengan metode kualitatif melalui pendekatan kritis (Fitrah, 2018) terhadap dominasi atas teknologi terhadap pemenuhan paket data seluler mahasiswa IAIN Kediri. Pendekatan ini digunakan untuk menjelaskan serta mengkritisi bagaimana dominasi teknologi terhadap kalangan mahasiswa khususnya mahasiswa IAIN Kediri melalui pemenuhan kebutuhan akan paket data seluler tersebut. Pengumpulan data dilakukan melalui 3 cara yaitu observasi, wawancara dan dokumentasi. Penentuan informan menggunakan purposive sampling yang disesuaikan dengan fokus penelitian, yakni mereka yang berkebutuhan akan internet dengan melalui paket data, bukan wifi. Dengan informan sebanyak 64 orang, 30 orang dari jurusan Ushuluddin dan Ilmu sosial, 20 orang dari jurusan Tarbiyah dan 14 orang lagi berasal dari jurusan Syari'ah. Data yang diperoleh dianalisis dengan menggunakan pendekatan kritis Herbert Marcuse.

\section{Hasil dan Pembahasan}

Saat ini, masyarakat sudah tidak lagi hidup dengan teknologi namun sudah dikontrol oleh teknologi. Hal ini dibuktikan dengan adanya kebutuhan akan paket data yang sudah menjadi kebutuhan primer sebagai seorang mahasiswa disamping kebutuhan akan makan, biaya tugas dan sebagainya (Simarmata, 2020). Semua informan menganggap bahwa membeli paket data seluler setiap bulannya adalah sesuatu yang sangat dibutuhkan. Harus ada biaya yang disisihkan atau memang sudah disiapkan untuk membeli paket data seluler ini.

Ketika seorang mahasiswa tidak memiliki akses terhadap internet, maka ia akan merasa seperti suatu kehampaan, karena tidak dapat mengakses berbagai hal misalnya ${ }_{2}$ ia menjadi tidak update akan informasi tugas, materi kuliah, sosial media atau hal lain yang membutuhkan internet untuk 
mengaksesnya. Hal ini sesuai dengan apa yang dikatakan oleh Herbert Marcuse bahwasannya apa yang dilakukan oleh manusia harus mendapatkan afirmasi dari teknologi (Marcuse, 2013). Afirmasi teknologi sebagaimana dipaparkan Marcuse, dominasi teknologi secara terus memberi kebebasan atas rasionalitas teknologis, posisi inilah disebut sebagai pasca-rasionalitas saat pesatnya perkembangan teknologi.

Pemikiran manusia sudah tidak original lagi karena untuk melakukan sesuatu harus mendapatkan pengakuan dari massa (Jamaludin, 2020). Akhirnya mereka menjadi manusia satu dimensi yang memiliki pemikiran yang sudah tidak original karena terpaku pada teknokratisme. Keadaan ini sangat sesuai dengan realita bahwasannya ketika smarthphone milik mahasiswa tidak memiliki akses internet maka ia akan bingung, bisa berfikiran yang negatif. Misalnya ketika tiba-tiba ada pengumuman mendadak mengenai jam perkuliahan dikelas atau berhubungan dengan tugas maka ia akan tertinggal oleh teman-temannya yang lain.

Bagi Marcuse, masyarakat industri maju adalah masyarakat yang tidak sehat karena masyarakat tersebut berdimensi satu, yakni segala kegiatan diarahkan pada satu tujuan saja, yaitu keberlangsungan dan peningkatan sistem yang telah ada, tidak lain adalah sistem kapitalisme yang ditopang oleh sistem teknologi dan informasi (Sudarminta, 2000:123). Ketika kegiatan seorang mahasiswa membutuhkan afirmasi dari teknologi, maka disitulah ia harus menggunakan teknologi dalam hal ini internet untuk mendapatkan apa yang diinginkannya. Hal ini ia lakukan ketika paket data seluler selalu tersambung di smartphone nya, padahal jika ditelisik lebih jauh maka dengan membeli paket data tersebut sebenarnya yang paling diuntungkan adalah provider penyedia layanan kartu prabayar. Karena akses akan internet intensitasnya semakin meningkat di setiap waktunya, maka keuntungan yang didapatkan juga akan semakin banyak pula. 
Selanjutnya, bahwasannya internet saat ini telah menjadi suatu patokan informasi bagi semua orang bahkan di berbagai bidang dan aspek pengetahuan, khususnya bagi mahasiswa yang memiliki tuntutan akan berbagai macam tugas, maka ketika mereka tidak menemukan referensi berupa buku kepustakaan, akhirnya referensi yang paling mudah didapatkan adalah melalui e-book atau berbagai macam jurnal yang sudah tersedia di internet (Alwi, 2021). Hal ini berlaku dan diterapkan juga oleh mahasiswa IAIN Kediri, tidak hanya digunakan untuk referensi tugas, sebagai bahan diskusi atau untuk keperluan lain, seringkali mereka membutuhkan akses paket data seluler untuk mendapatkan informasi yang mereka butuhkan seputar perkuliahan atau bahkan diluar perkuliahan.

Apalagi bagi mereka yang sedang mengerjakan skripsi, internet menjadi suatu kebutuhan yang amat sangat urgent, misalnya digunakan untuk sekedar menambah referensi tambahan, alat penyambung komunikasi dengan teman sebaya atau bahkan dengan dosen pembimbing skripsi. Realita yang terjadi pada mahasiswa IAIN Kediri ini sesuai dengan kritikan Herbert Marcuse terhadap masyarakat modern yang bersifat One Dimensional yang tampak pada segala aspek, yakni ilmu pengetahuan, seni, filsafat, pemikiran sehari-hari, sistem politik, ekonomi dan teknologi (Jalalulai, 2019). Manusia modern kehilangan daya dan prinsip kritis. Masyarakat modern baik benda maupun manusia direduksi menjadi sesuatu yang fungsional saja, terlepas dari substansi dan otonomi.

Prinsip kritis Marcuse ini diambil dari konsep-konsep filsafat yang yang memungkinkan orang untuk memahami kebebasan, keindahan, akal budi, kegembiraan hidup dan lain sebagainya. Pada zaman ini, seharusnya masyarakat perlu kembali kepada konsep kebenaran sebagai kenyataan itu sendiri. Konsep kebenaran yang dimaksud adalah bersifat normatif, mengatasi taraf empiris dan taraf logika formal dari Aristoteles (Marcuse, 
1964:127-130). Masyarakat di zaman modern ini tidak lagi didominasi oleh manusia seperti pada saat zaman Karl Marx, akan tetapi masyarakat telah didominasi oleh sesuatu yang anonim yakni sistem teknologi yang totalitas dan mencengkeram segala kenyataan alamiah dan sosial manusia (Marcuse, 1964:154-156). Sebagaimana Adorno dan Horkheimer, melihat konsekwensi modernitas atas realitas teknologis begitupun Marcuse berbicara mengenai rasionalitas teknologis sebagai karakteristik rasionalitas zaman ini.

Teknologi seperti akhirnya mengontrol setiap hal yang dilakukan oleh mahasiswa tanpa bisa untuk keluar maupun protes mengapa ia layaknya yang dijalankan bukan sebagai yang menjalankan. Karena ketika misalnya seorang mahasiswa membutuhkan informasi secara cepat maka yang paling efektif dilakukan adalah mencarinya melalui internet (Rahmawati, 2018). Nah hal ini akan menjadi terhambat apabila paket data seluler yang mereka miliki habis. Mereka seperti secara otomatis diarahkan untuk memilikinya lagi dengan membeli yang baru agar koneksi internet yang ada dalam smartphone tetap lancar. Bagaimana kontrol seperti ini dianggap lumrah tanpa ada kata protes keberatan dari mahasiswa.

Dari 64 mahasiswa yang ditanya pada kebutuhan terhadap paket data, $85 \%$ dari mereka mengatakan jika paket data seluler mereka habis maka yang paling harus dilakukan adalah membeli yang baru sesegera mungkin, karena hal ini perlu, seakan-akan mereka akan merasakan hampa apabila tidak dapat menyambung ke internet, entah hanya digunakan untuk sosial media berupa aplikasi chatting atau untuk keperluan tugas, atau bahkan bagi mereka penggila game online. Sedangkan dua orang yang menganggap biasa-biasa saja apabila tidak memiliki sambungan internet di hape mereka mengatakan bahwasannya paket data tersebut bukan suatu hal yang sangatlah urgent apabila sehari-duahari tidak memilikinya pun tidak masalah. 
Karena informasi juga bisa didapatkan dari teman lain yang dekat misalnya. Atau karena ia menganggap bahwa internet bukan suatu yang urgent jika hanya digunakan untuk sekedar bersenang-senang saja, hal ini berbeda ketika memasuki musim ujian UTS atau UAS, maka paket data seluler wajib dimiliki. Artinya, yang seharusnya kebebasan untuk berselancar di internet dengan berbagai kemudahan yang ditawarkan oleh penyedia provider kemudian menjadi alat dominasi lain. Lenyapnya negasi terhadap dominasi sistem teknologis merupakan ciri dari zaman sekarang yang meliputi bidang sosial, politik, budaya, kesenian, ekonomi dan ilmu pengetahuan. Karena itu, masyarakat menjadi satu dimensi, seluruh dimensi masyarakat mengarah kepada satu tujuan saja, yaitu menjaga kelangsungan sistem teknologis yang telah menjadi penguasa tunggal dan total dalam mendominasi (Surahman, 2016:31-42).

Kemudian, ada tiga ciri-ciri masyarakat modern yang sesuai dengan bagaimana dominasi teknologi atas pemenuhan paket data seluler ini, yang pertama adalah masyarakat berada dibawah kekuasaan prinsip teknologi, yaitu suatu prinsip yang segala tekanannya dikerahkan untuk memperlancar, memperluas dan memperbesar produksi. Kemajuan manusia disamakan dengan terciptanya perluasan teknologi (Azmi, 2019). Nah, mahasiswa sebagai pengguna teknologi mau tidak mau harus memiliki akses internet ketika masa aktif perkuliahan.

Hal ini akan berdampak terhadap produksi provider penyedia layanan paket data berbayar semakin mendapatkan keuntungan karena produk barang yang mereka hasilkan harus selalu laku dipasaran dengan kriteria-kriteria tertentu sesuai dengan pasar yang mereka tuju, ketika diarahkan kepada mahasiswa maka harus dengan harga terjangkau, fasilitas memadai maupun segala kemudahan yang harus ada jika membeli paket data seluler tersebut. Yang kedua masyarakat menjadi irasional secara keseluruhan. Sebab terjadi 
kesatuan antara produktivitas (penghasilan) dan destruktivitas (penghancuran).

Kekuatan produksi bukan digunakan untuk perdamaian, melainkan untuk menciptakan potensi-potensi permusuhan dan kehancuran (Dewi, 2013). Yang ketiga adalah masyarakat berdimensi satu (one dimensional society). Inilah ciri yang paling fundamental. Segala segi kehidupannya diarahkan pada satu tujuan, yakni meningkatkan dan melangsungkan satu sistem yang telah berjalan. Manusia tidak memiliki lagi dimensi-dimensi lain; bahkan, dengan satu tujuan itu, dimensi-dimensi lain justru disingkirkan (Etzioni, 2010).

Seperti yang kita tahu, bahwa ketika membeli paket data seluler maka akan lebih ekonomis daripada harus membeli pulsa manual. Sebab sudah tertera berapa banyak paket data yang disediakan oleh provider sehingga kita bisa mengira-ngira berapa banyak data yang dihabiskan untuk berselancar di internet serta berapa lama masa aktiv dari paket data tersebut. Tentu saja hal ini akan sangat memudahkan mahasiswa dalam penggunaannya yang relatif instan dengan harga yang sangat terjangkau dikantung mahasiswa apalagi yang notabene orang rantau.

Akan tetapi dibalik hal tersebut menurut Marcuse Perkembangan teknologi modern telah menciptakan alat-alat produksi baru yang dengan mekanisasi, standarisasi, dan otomatisasi seharusnya dapat semakin membebaskan manusia dari keharusan kerja berat (Richta, 2018). Namun dalam kenyataannya justru memaksakan tuntutan-tuntutan ekonomis dan politisnya untuk tetap mempertahankan dan bahkan meningkatkan waktu kerja dengan motif mengejar keuntungan (Nam, 1988:133-147). Jika mahasiswa zaman dahulu semua rujukan adalah buku kepustakaan, maka mahasiswa sekarang banyak mengandalkan internet walau tidak sepenuhnya, nah hal inilah yang dikatakan kemudahan, mudah dalam hal mencari dengan 
waktu yang cukup instan meskipun hasil yang didapatkan belum tentu akurat. Kemudahan inilah yang sebenarnya merupakan suatu keuntungan sendiri bagi mereka-mereka kaum kapitalis.

Penambahan waktu kerja dengan bantuan tekonologi atau alat-alat produksi modern telah mampu meningkatkan hasil produksi. Untuk mencegah turunnya harga yang berimbas pada berkurangnya keuntungan diciptakanlah suatu jaringan ekonomi dengan manajemen yang rapi melalui manipulasi kebutuhan dan ekspansi ekonomi ke negara-negara yang sedang berkembang. Pada saat produksi yang mereka hasilkan semakin meningkat, maka sebenarnya tujuan utama ekspansi mereka (kaum kapitalis) adalah negara berkembang yang terkadang hanya sebagai konsumen pasif, hanya menerima semua hasil produksi tanpa mengkritisi sebenarnya apa yang mereka nikmati dari hasil industrialisasi tersebut berdaya guna atau hanya sekedar sesuatu yang tanpa bisa dirasakan manfaatnya.

Mahasiswa dalam memilih untuk membeli paket data adalah ada 2 faktor, mereka memilih untuk membeli paket data seluler dari provider A karena memang ia butuh dengan layanan yang mumpuni, atau faktor kedua yakni hanya sebagai eksistensi saja, misalnya ia membeli paket data seluler dari Provider B bukan karena ia membutuhkan tapi supaya dikatakan keren oleh temannya, misal ketika ia membeli paket data dengan harga yang mahal namun tidak terlalu dibutuhkan layanan yang ditawarkan oleh provider B tersebut.

Mengenai masalah pemenuhan kebutuhan tersebut, Marcuse memberi cara pandang yang lebih mendalam dan menyentuh makna esensial kebebasan. Dalam pandangannya, kebebasan memilih bukan faktor yang menentukan untuk mengukur tingkat kemerdekaan individu, selama apa yang dapat dan akan dipilih ditentukan bahkan dipaksakan oleh sistem di luar mereka. Memuaskan insting berbeda dari sikap memperbudak diri lewat 
insting di bawah kekuasaan pihak lain yang memberikan segala kepuasan. Bagi Marcuse, pemuasan sejati adalah pemenuhan yang mendukung perkembangan dan perwujudan diri secara bebas. Jika dilihat dari realita yang terjadi di Mahasiswa, terkadang mereka membeli sesuatu bukan karena mereka membutuhkan, hanya saja mereka membeli untuk mencapai suatu kepuasan tertentu.

Pemenuhan kebutuhan akan akses internet berupa paket data internet oleh mahasiswa IAIN Kediri sudah mencapai taraf kebutuhan primer seperti pemenuhan atas kebutuhan makan sehari-hari walau intensitasnya tidak sesering makan, akan tetapi ketika paket data habis harus segera membeli lagi, jika tidak terpenuhi, maka seakan-akan mereka merasakan kehampaan (Sihotang, 2009:14). Bisa dikatakan bahwasannya inilah kebutuhan semu. Penciptaan kebutuhan semu oleh ekonomi dan politik kapitalisme yang telah melembaga telah menciptakan semacam kodrat kedua dalam diri manusia yang mengikatnya secara libdinal (dorongan nafsu) dan membuat mereka menjadi agresif pada barang-barang.

Kebutuhan-kebutuhan semu yang telah di-introyeksikan (istilah ini digunakan oleh Marcuse untuk pengertian dimasukkan sedalam-dalamnya) pada masing-masing individu telah menjadi kebutuhan biologis (kebutuhan pokok yang harus dipenuhi) yang apabila tidak dipenuhi akan menimbulkan frustasi pada diri manusia. Kodrat kedua tersebut telah membentuk sikap mendukung sistem yang ada dan menentang setiap perubahan yang akan merenggut serta membebaskan mereka dari ketergantungan pada pasar yang semakin penuh dengan barang-barang dagangan.

Tidak bisa dipungkiri bahwa struktur pasar selalu merupakan pemerasan dan penguasaan, karena motif mengejar keuntungan akan mendorong produsen untuk menguasai konsumen, baik dengan memeras buruh [yang tidak lagi dilakukan secara fisik] maupun dengan memanipulasi 
kebutuhan masyarakat (Feher, 2021). Dari kondisi tersebut, akhirnya nampak dengan jelas bahwa produsenlah yang berkuasa dan menentukan kehidupan dalam masyarakat. Proses produksi dan distribusi kapitalisme modern telah mengubah bentuk pemerasan dan penguasaan tersebut. Dengan tertanamnya kehausan untuk terus membeli barang-barang produksi yang baru, produsen seakan-akan hanya menuruti saja permintaan dari masyarakat.

Hukum penawaran dan permintaan membangun suatu keselarasan antara yang memerintah dan diperintah. Keselarasan itu benar-benar telah terbangun sejauh produsen dapat menciptakan masyarakat yang selalu haus akan barang-barang produksinya. Marcuse menegaskan:

"No matter how much such needs may have become the individual's own, reproduced and fortified by the conditions of his existence; no matter how much he identifies himself with them and finds himself in their satisfaction, they continue to be what they were from beginning-products of a society whose dominant interest demands repression".

Melihat betapa kebutuhan akan pemenuhan paket data seluler oleh mahasiswa IAIN Kediri ini berarti dari sisi sosial ekonomi. Dengan kebutuhan tersebut maka mereka bisa disebut sebagai masyarakat industri modern atau "One Dimensional Man” dalam bidang sosial ekonomi terlihat dalam gerak hidup ke arah peningkatan produksi demi mengejar keuntungan yang semakin besar. Gerak hidup demikian telah mengorbankan kemampuan-kemampuan manusia serta menghapus kebebasan individu untuk menentukan diri.

Di bidang budaya, kemajuan teknologi telah meleburkan oposisi dan distingsi antara realitas sosial dan budaya adi luhung atau kebudayaan sejati (highculture). Pada masa pra teknologis, manusia dan alam masih berdampingan sebagai entitas yang masing-masing otonom, namun dalam era teknologi manusia dan alam diubah menjadi sarana dan objek (Gell, 2021). Perubahan status dan fungsi ini mempengaruhi muatan budaya dalam 
realitas teknologis. Hal ini juga berlaku bagi mahasiswa, bahwasannya mereka lebih percaya atau merasakan tentram apabila mengetahui pengumuman atau informasi melalui media sosial, misalnya mengenai tugas perkuliahan, daripada seperti zaman dahulu yang menyampaikan informasi melalui face to face dari mulut ke-mulut atau melalui papan pengumuman. Ketika seperti saat ini dengan adanya website kampus yang menyediakan berbagai informasi, maka penggunanya lebih menggunakan cara instan berupa mencari informasi melalui internet daripada mencari informasi langsung ke-akademik misalnya.

Dapat dipahami bahwasannya bahwa ciri khas yang menonjol dalam masyarakat industri adalah peranan ilmu pengetahuan dan teknologi yang demikian besar. Ilmu pengetahuan dan teknologi telah merubah secara radikal cara manusia dalam mengelola masyarakat dan alam lingkungannya (Spaargaren, 1992:323). Radikalitas tersebut terutama disebabkan oleh dominasi pola pikir mekanistis dan positivistis yang menjadi salah satu ciri masyarakat modern atau kapitalis.

Manusia dan alam difungsikan sebagai objek eksploitasi melalui penggunaan perangkat teknis, sehingga pada taraf ini teknologi sudah berubah menjadi alat reifikasi (re:penilaian bahwa kesuksesan diukur dari sejumlah benda-benda yang dimiliki)dalam format yang sangat canggih dan handal.Ketika permasalahan seperti diatas dialami oleh mahasiswa, jika menelaah menggunakan pemikiran Marcuse, ia menawarkan kepada kehidupan manusia untuk tidak menyerahkan kemauannya kepada sistem teknologis, yang membuat manusia sebagai budak teknologi tanpa ada usaha kreatif dan inovatif dari manusia. 


\section{Kesimpulan}

Di era sekarang, masyarakat sudah tidak lagi hidup dengan teknologi namun sudah dikontrol oleh teknologi. Hal ini dibuktikan dengan adanya kebutuhan akan paket data yang sudah menjadi kebutuhan primer sebagai seorang mahasiswa disamping kebutuhan akan makan, biaya tugas dan sebagainya. Inilah yang disebut oleh Herbert Marcuse bahwasannya masyarakat modern adalah One Dimensional Man. apa yang dilakukan oleh manusia harus mendapatkan afirmasi dari teknologi. Pemikiran manusia sudah tidak original lagi karena untuk melakukan sesuatu harus mendapatkan pengakuan dari massa. Akhirnya mereka menjadi manusia satu dimensi yang memiliki pemikiran yang sudahtidak original karena terpaku pada teknokratisme. Hal inilah yang terjadi terhadap mahasiswa IAIN Kediri sebagai pengguna paket data seluler yang membutuhkan layanan tersebut selayaknya sebagai kebutuhan primer yang harus selalu terpenuhi, karena ketikahandphone yang mereka miliki tidak memiliki akses terhadap internet maka mereka tidak akan bisa mengetahui berbagai macam informasi muladari kegiatan perkuliahan sampai dengan informasi-informasi lain. Dari hal tersebut menimbulkan dampak tidak hanya positif berupa kemudahan-kemudahan namun juga negatif yang mengarah kepada kehancuran. Oleh karenanya Marcuse menawarkan kepada kehidupan manusia untuk tidak menyerahkan kemauannya hanya kepada sistem teknologis, tapi harus ada usaha kreatif dan inovatif dari manusia. 


\section{Daftar Pustaka}

Alwi Hilir, Kom, S. 2021. TEKNOLOGI PENDIDIKAN DI ABAD DIGITAL. Klaten: Lakeisha.

Azmi, N. 2019. Kritik Herbert Marcuse Terhadap Globalisasi Dalam Perspektif Islam (Doctoral dissertation, UIN Walisongo).

Dewi, N. Y. 2013. ONE DIMENSIONAL MAN (Studi Terhadap Kritik Herbert Marcuse Mengenai Masyarakat Modern)(Doctoral dissertation, Universitas Islam Negeri Sultan Syarif Kasim Riau).

Etzioni, A. 2010. Moral Dimension: Toward A New Economics. New York: Simon and Schuster.

Feher, M. 2021. Rated Agency: Investee Politics in a Speculative Age. New Jersey: Princeton University Press.

Fitrah, M. 2018. Metodologi Penelitian: Penelitian Kualitatif, Tindakan Kelas \& Studi Kasus. Sukabumi: CV Jejak (Jejak Publisher).

Gell, A. 2021. The Anthropology of Time: Cultural Constructions of Temporal Maps and Images. London: Routledge.

Herbert Marcuse. 1964. One Dimensional Man: Studies of Advanced Industrial Society. London: Routledge and Kegan Paul Ltd. 127-130

Herbert Marcuse. 1964. One Dimensional Man; Studies of Advanced Industrial Society. London: Routledge and Kegan Paul Ltd. 123-124

Jalalulail, H. I. 2019. Kritik Herbert Marcuse Terhadap Ideologi Modern (Doctoral Dissertation. UIN Sunan Gunung Djati Bandung.

Jamaludin, J., Purba, R. A., Effendy, F., Muttaqin, M., Raynonto, M. Y., Chamidah, D., \& Puspita, R. 2020. Tren Teknologi Masa Depan. Medan: Yayasan Kita Menulis.

Marcuse, H., \& Kellner, D. 2013. Towards a Critical Theory of Society: Collected Papers of Herbert Marcuse, Volume 2. London: Routledge.

Nam, C. H., \& Tatum, C. B. 1988. Major Characteristics of Constructed Products and Resulting Limitations of Construction Technology. Construction Management and Economics, 6(2), 133-147.

Pratama, D. A. N. 2019. Tantangan Karakter Di Era Revolusi Industri 4.0 Dalam Membentuk Kepribadian Muslim. Al-Tanzim: Jurnal Manajemen Pendidikan Islam, 3(1), 198-226.

Rahmawati, D. 2018. Millennials and I-Generation Life. Yogyakarta: Laksana.

Richta, R. 2018. Civilization at the Crossroads: Social and Human Implications of the Scientific and Technological Revolution (International Arts and Sciences Press): Social and Human Implications of the Scientific and Technological Revolution. London: Routledge.

Sihotang, K. 2009. Kekerasan: Wujud Kehampaan Eksistensi Sebuah Tinjauan Etis atas Pemikiran Erich Fromm. Respons: Jurnal Etika Sosial, 14(02).

Simarmata, J., Chaerul, M., Mukti, R. C., Purba, D. W., Tamrin, A. F., Jamaludin, J. \& Meganingratna, A. (2020). Teknologi Informasi: Aplikasi dan Penerapannya. Medan: Yayasan Kita Menulis. 
Spaargaren, G., \& Mol, A. P. 1992. Sociology, Environment, and Modernity: Ecological Modernization as a Theory of Social Change. Society \& Natural Resources, 5(4), 323-344.

Sudarminta, J. 2000. Etika Umum Kajian Tentang Beberapa Masalah Pokok dan Teori Etika Normatif. Yogyakarta: Kanisius

Surahman, S. 2016. Determinisme Teknologi Komunikasi Dan Globalisasi Media Terhadap Seni Budaya Indonesia. Rekam: Jurnal Fotografi, Televisi, Animasi, 12(1), 31-42.

Zahid, A. 2019. Sensualitas Media Sosial di Era Globalisasi (Kajian Sosiologi Media McLuhan sebagai Analisis Media Masa Kini). Jurnal Sosiologi USK (Media Pemikiran \& Aplikasi), 13(1), 1-15. 